\title{
ACOLHIDA DE CALOUROS DE ENGENHARIA COM CAPACITAÇÃO E MÃO NA MASSA EM ROBÓTICA AUTÔNOMA
}

Joseph Rodrigues Oliveira-josephscgo@gmail.com

Deric Teixeira Soares - derictsoares@gmail.com

Lohan da Silva Nolasco - lohannolasco.00@gmail.com

Ketcho Henrique Fistel - ketcho@alunos.utfpr.edu.br

Larissa dos Santos Paulo - larissapaulo14@gmail.com

Roberto Cândido-robertocandido@utfpr.edu.br

Miguel Antonio Sovierzoski-miguelaso@utfpr.edu.br

Universidade Federal Tecnológica do Paraná - UTFPR

Av Sete de Setembro, 3165,

80230-901 - Curitiba - Paraná

Resumo: Este trabalho apresenta o projeto de extensão de acolhida de calouros de Engenharia de Controle e Automação e de Engenharia Elétrica realizado no primeiro semestre de 2020. O projeto foi desenvolvido por um instrutor e uma equipe de monitores e consistiu de uma capacitação para robótica autônoma em robô seguidor de linha. O projeto teve uma exposição teórica e tecnológica com componentes e módulos eletrônicos, e a parte mão na massa para construírem, resolverem os problemas apresentados e fazerem funcionar o robô seguidor de linha. De forma lúdica, foram apresentados problemas de engenharia e foram utilizados conhecimentos, saberes e habilidades para resolvê-los. Tivemos 13 calouros que participaram do projeto. Foram divididos em 5 equipes pelos seus conhecimentos e habilidades anteriores, sendo que 3 robôs funcionaram adequadamente.

Palavras-chave: Acolhimento de Calouros. Curso de Acolhimento. Robótica Autônoma. Robô Seguidor de Linha. Robô Segue-Faixa.

\section{INTRODUÇÃO}

No acolhimento de calouros de graduação em Engenharia, que na nossa universidade ocorre na semana anterior ao início do semestre letivo, a universidade promove diversas atividades como palestras com coordenadores de cursos e professores convidados, visitação as estruturas e laboratórios, visita a biblioteca, visita aos departamentos, e os diretórios acadêmicos também fazem a sua iteração com os calouros.

Um projeto de extensão foi iniciado nesta semana de acolhimento com a capacitação de calouros para competição de robô seguidor de linha (line follower robot), ou robô segue-faixa. Essa atividade iniciou com um stand onde um robô seguia uma faixa escura descrita numa mesa de superfície clara, apresentada na figura 1. O movimento do robô autônomo de duas rodas atraiu alguns calouros interessados em participar do projeto de extensão. 
Figura 1 - Stand do projeto de extensão capacitação para competição de robô seguidor de linha na semana de acolhimento dos calouros.

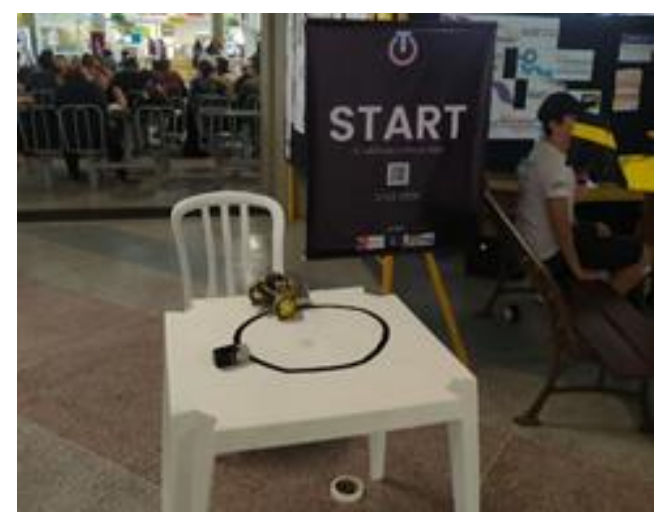

Fonte: autoria própria, com autorização.

Este trabalho descreve o projeto de extensão desenvolvido no primeiro semestre de 2020, e as primeiras impressões dessa experiência no acolhimento de calouros de engenharia. As atividades presenciais da universidade foram paralisadas na semana seguinte devido a pandemia do COVID-19.

\section{PROJETO DE EXTENSÃO CAPACITAÇÃO EM ROBÔ SEGUIDOR DE LINHA}

O projeto de extensão de capacitação para a competição de robô seguidor de linha foi desenvolvido por um professor instrutor e por alunos monitores, que auxiliaram e interagiam com os calouros. As atividades do projeto ocorreram nas duas primeiras semanas do semestre letivo, em dois períodos sem aulas, e em dois sábados, totalizando 20 horas.

\subsection{Objetivo do projeto de extensão}

Aproveitando a empolgação e o entusiasmo dos calouros no início do semestre letivo, adaptando-se a nova estrutura da universidade, a novos colegas, este projeto de extensão consistiu em capacitar os calouros interessados por robótica autônoma, a entender o que é, montar, programar, testar e avaliar o seu robô seguidor de linha, como atividade para incentivar, motivar e inspirar a engenharia, além de ser uma ferramenta de desenvolvimento técnico para o aluno.

\subsection{Desafios do projeto de extensão}

O desafio para a equipe do projeto foi motivar os calouros a acompanharem as atividades e perceberem que estão recebendo conhecimentos de componentes eletrônicos, de sistema eletromecânico, de sistemas microcontrolados, de interfaces, e mais especificamente da plataforma Arduino (ARDUINO_1), que é uma ferramenta de baixo custo podendo ser utilizada no desenvolvimento de atividades técnicas acadêmicas.

O desafio para os calouros foi entender e assimilar os conhecimentos apresentados, interagir com a sua equipe e utilizarem estes conhecimentos para resolverem os problemas de projeto, desenvolvimento, programação e testes do robô seguidor de linha. 


\subsection{Dinâmica do projeto de extensão}

O projeto envolveu três abordagens e momentos distintos: exposição teórica; iteração com componentes, módulos eletrônicos e programação; e atividade mão na massa para montar e fazer funcionar o robô seguidor de linha.

\section{Exposição teórica e dinâmicas no primeiro momento}

Apresentação pelo instrutor de conteúdos técnicos, de forma expositiva, interagindo com elementos da memória afetiva e de uso cotidiano dos calouros. Nesse momento, era apresentado um novo conhecimento e agregando com conhecimentos anteriores, executava-se uma atividade de demonstração ou uma atividade prática de fixação para os calouros executarem.

\section{Iteração com componentes do robô num segundo momento}

Iteração dos calouros com os monitores para reconhecimento e contato com elementos do robô seguidor de linha. Nesse momento, o professor não estava presente, e os monitores iteragiram com os calouros para o levantamento da lista de materiais que precisavam, o que seria disponibilizado na forma de empréstimo (para reduzir custos), e o que os alunos precisavam adquirir e providenciar para o terceiro momento.

\section{Mão na massa, desenvolvendo e testando as soluções de engenharia, terceiro momento}

Os calouros foram separados em equipes heterogêneas em termos de conhecimento tecnológico, e aproveitando as habilidades pessoais e os conhecimentos adquiridos executaram a montagem, desenvolveram a programação, e executaram testes do robô seguidor de linha.

\subsection{Desenvolvimento do projeto de capacitação}

O projeto consistiu em etapas sequenciais de capacitação com apresentação de conhecimentos e iteração com as memórias afetivas dos alunos, a integração de conhecimentos numa demonstração ou numa atividade prática de fixação para eles desenvolverem. É apresentada a sequência resumida de atividades desenvolvidas.

\section{Histórico da robótica móvel: LEGO, Arduino}

Foi apresentado um rápido histórico da robótica móvel, iniciada pela obra referência de Papert (1985), e materializada através da linha de produtos tecnológicos NXP e EV3 da LEGO (WIKIPEDIA_2, WIKIPEDIA_3), e mais recentemente com a linha de produtos de prototipação de hardware da Arduino (WIKIPEDIA_1, ARDUINO_1, ARDUINO_2), entre muitas outras tecnologias de robótica educacional existentes hoje em dia. Durante esta explanação, foi realizado o levantamento do conhecimento e habilidades de cada aluno participante, e sendo mapeado para a divisão em equipes com nível de conhecimento heterogêneo das tecnologias envolvidas com a robótica. Alguns calouros conheciam a plataforma LEGO, outros conheciam a plataforma Arduino, por terem utilizado anteriormente, e/ou por influência de um parente próximo trabalhar com Arduino em casa. Mas a maioria dos calouros não possuía conhecimentos prévios de robótica educacional, de Arduino e nem de linguagem de programação.

\section{Microcontrolador, entradas/saídas digitais}

Utilizando a ideia de um eletrodoméstico comum, um forno de microondas, ou de uma máquina de lavar, foi sendo apresentado de forma lúdica os conceitos de microcontrolador, o que deve conter e como interage com o mundo exterior através de sinais digitais de entrada e 
saída. E foi sendo apresentado um diagrama em blocos dos componentes, dos tipos de sinais digitais, sinais de entrada e sinais de saída, entre outros. (Monk, 2017, cap 1).

\section{Placa Arduino Uno}

O Arduino Uno é o modelo mais utilizado para aplicações iniciais com esta plataforma de prototipagem de baixo custo. Consiste em uma placa de circuito impresso com microcontrolador que disponibiliza os seus periféricos em pinos na borda da placa, como apresenta a figura 2 . Através dos conectores, o usuário pode fazer as conexões entre circuitos.

Figura 2 - Vista superior da placa Arduino Uno.

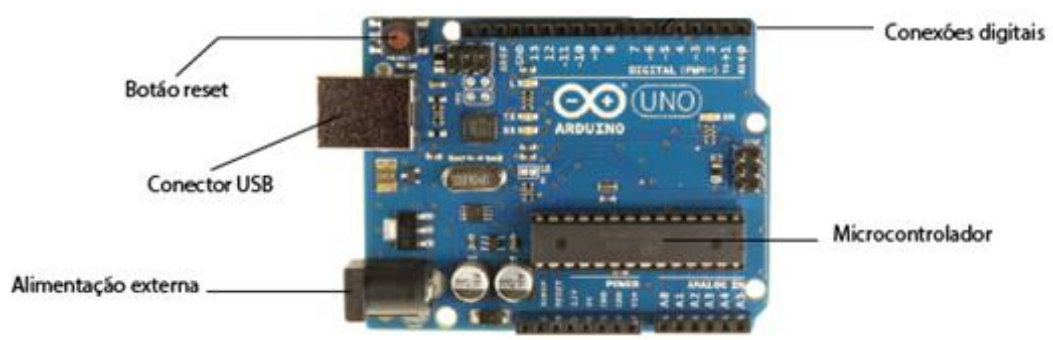

Fonte: alterado de Monk (2017).

\section{Arduino IDE, estrutura do sketch, programa exemplo Blink}

O Arduino IDE (Integrated Development Environment) é um conjunto integrado de aplicativos e ferramentas de software para auxiliarem o desenvolvimento e testes do programa. Nesse ambiente o programa é denominado de sketch. A figura 3 apresenta a tela do Arduino IDE com o programa exemplo "Blink".

Figura 3 - Ambiente Arduino IDE com o programa exemplo Blink.

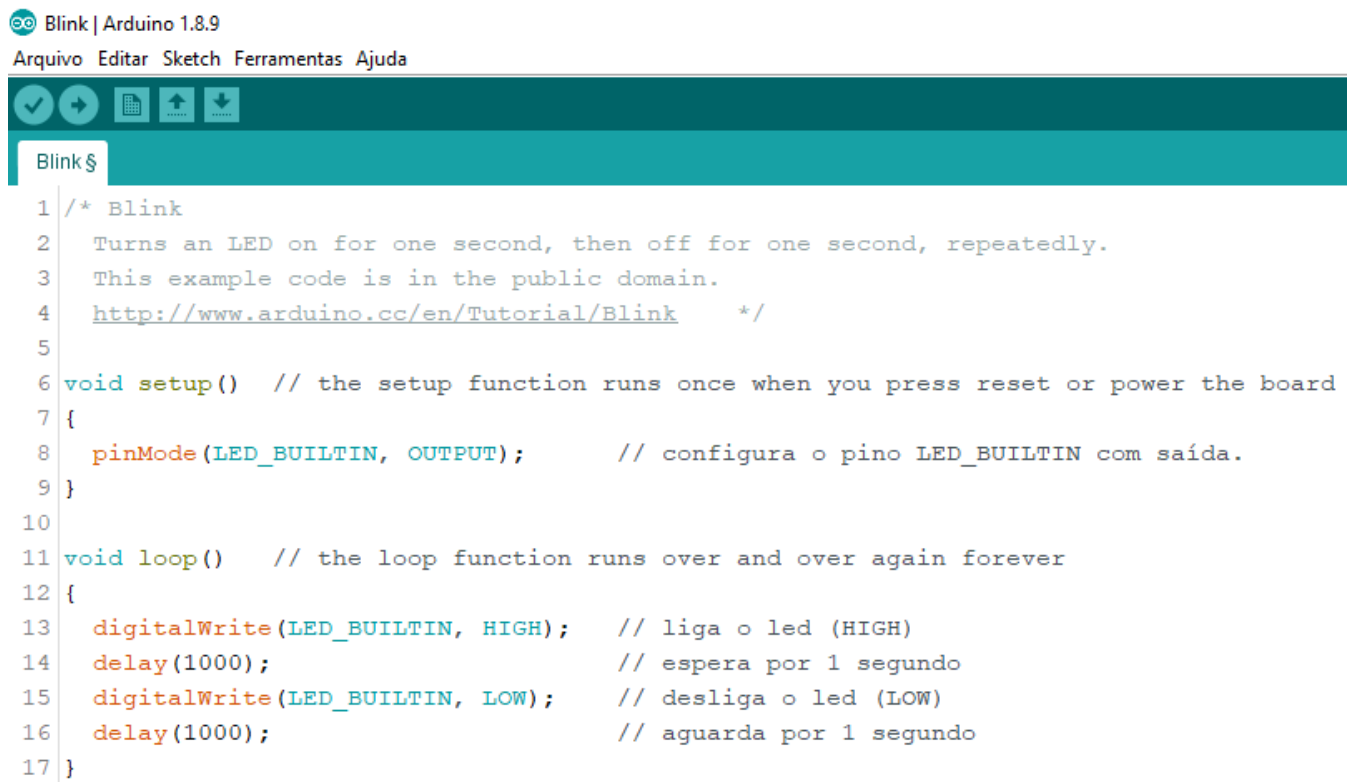

Fonte: autoria própria.

O programa exemplo Blink, disponível numa aba na IDE, fica piscando um led (lightemitting diode - diodo emissor de luz) disponível na placa Arduino Uno, com cadência de um segundo led aceso e um segundo led apagado. 
A estrutura do sketch é composta por duas funções: $\operatorname{setup}()$ e $\operatorname{loop}()$. A função $\operatorname{setup}()$ é executada uma única vez, sendo destinada a configurações de hardware, e a função $\operatorname{loop}()$ é o programa principal sendo executada repetidamente.

$\mathrm{Na}$ sequência da atividade, os calouros utilizam a interface IDE e o Arduino Uno para exercitarem e fixarem os conhecimentos. É solicitado para que alterem os valores de tempo de led aceso e tempo de led apagado, para que se familiarizem com o Arduino IDE.

Foram apresentadas as variáveis do tipo int, e a estrutura do comando de decisão if-else, e realizados alguns exercícios de fixação e desafios, para desenvolverem as habilidades de lógica de programação e de pensamento computacional (Monk, 2017).

Pensamento Computacional (WIKIPEDIA_4) é resumidamente o processo de pensamento humano envolvido na formulação de um problema e na expressão de sua solução em etapas de forma que uma máquina execute. No nosso caso, o pensamento computacional é desenvolver o programa para o controle autônomo do robô seguidor de linha.

\section{Característica de radiação infravermelha e Módulo sensor de linha}

Os materiais possuem a capacidade de refletir ou absorver a radiação infravermelha (InfraRed - IR) dependendo da cor clara ou escura, ilustrado na figura 4(a). O componente TCRT5000 possui o transmissor IR e o sensor IR no mesmo encapsulamento e é utilizado no módulo sensor de linha apresentado na figura 4(b). Uma das saídas do módulo sensor de linha é sinal digital, facilitando o uso, indicando superfície clara, ou superfície escura (fita preta).

Figura 4 - (a) Característica de reflexão de infravermelho, (b) Módulo eletrônico sensor de linha.

(a)

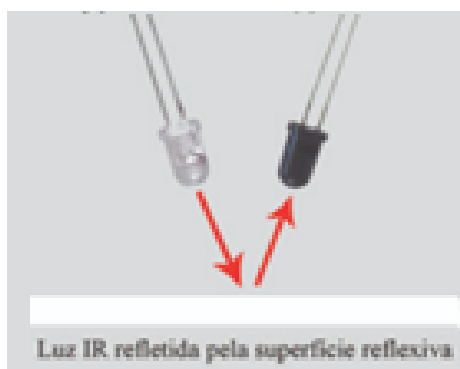

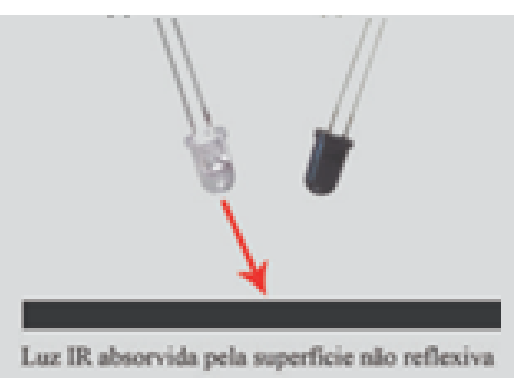

Fonte: autoria própria.

\section{Motor de corrente contínua com caixa de redução}

O motor de corrente contínua (motor cc) opera com velocidade elevada e baixo torque. Quando acoplado a uma caixa mecânica de redução, a velocidade de rotação diminui e o torque aumenta. Este tipo de motor e caixa de redução, apresentado pela figura 5(a), é utilizado em robótica educacional e robôs de duas rodas ( $2 \mathrm{wd}-T w o$-wheel drive) e de quatro rodas (4wd).

\section{Driver de potência Ponte $\mathrm{H}$}

Para realizar o driver de potência do motor e permitir a mudança de sentido de rotação utiliza-se um dispositivo denominado ponte $\mathrm{H}$. Utilizando a memória afetiva dos calouros, referimo-nos ao vidro elétrico dos carros, onde o comando de subir e descer do vidro é realizado por uma chave eletromecânica, acionada pelo usuário, que faz a função de ponte $\mathrm{H}$, apresentada na figura 5(b). No robô seguidor de linha o Arduino controla a ponte $\mathrm{H}$, então utilizamos uma ponte $\mathrm{H}$ com transístores, como o circuito integrado L293H, apresentada pela figura 5(c).

Com a ponte $\mathrm{H}$, pode-se ligar o motor em um sentido de rotação, inverter o sentido de rotação invertendo-se o sentido da corrente no motor, e desligar o motor. 
Figura 5 - (a) Motor de corrente contínua para tensão de 3 a 6 volts, com caixa de redução e roda plástica.

(b) Ponte H com chaves, (c) Ponte H L293H com transístores.

(a)

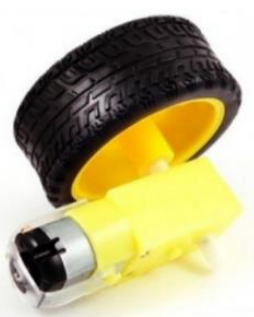

(b)

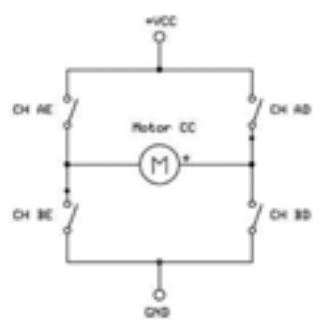

Fonte: autoria própria.
$\mathrm{Ol}$ a $\mathrm{O3}$ de dezembro (c)

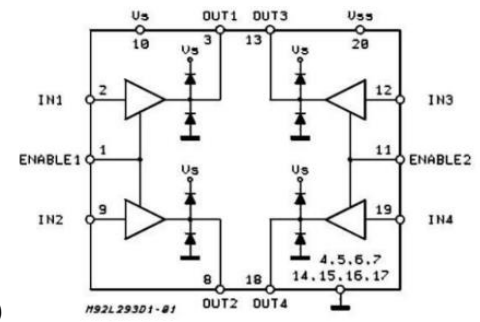

\section{Interface PWM, ciclo de trabalho}

A interface PWM (Pulse Width Modulation - modulação por largura de pulso) executa uma modulação na alimentação do motor, alterando o ciclo de trabalho (duty cycle) de 0 a $100 \%$, resultando em tensão eficaz de 0 a 6 volts no motor. A velocidade de rotação do motor cc é proporcional a tensão. A figura 6 apresenta diversas situações de ciclos de trabalho.

Figura 6 - Sinal PWM com diversos ciclos de trabalho.

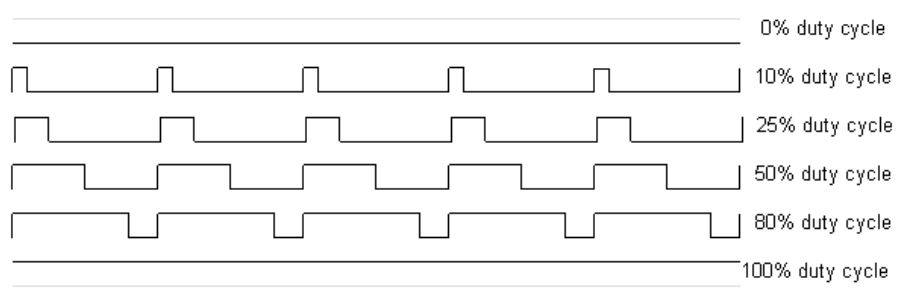

Fonte: autoria própria.

O Arduino Uno possui diversos periféricos de interfaces PWM, conectados a pinos de saída para facilmente executar este tipo de controle pelo usuário. A figura 7 apresenta um sketch para exercitar o motor cc entre a velocidade 100 e 255, sendo incrementada a cada 30 millisegundos.

Figura 7 - Sketch para teste de velocidade do motor cc com sinal PWM.

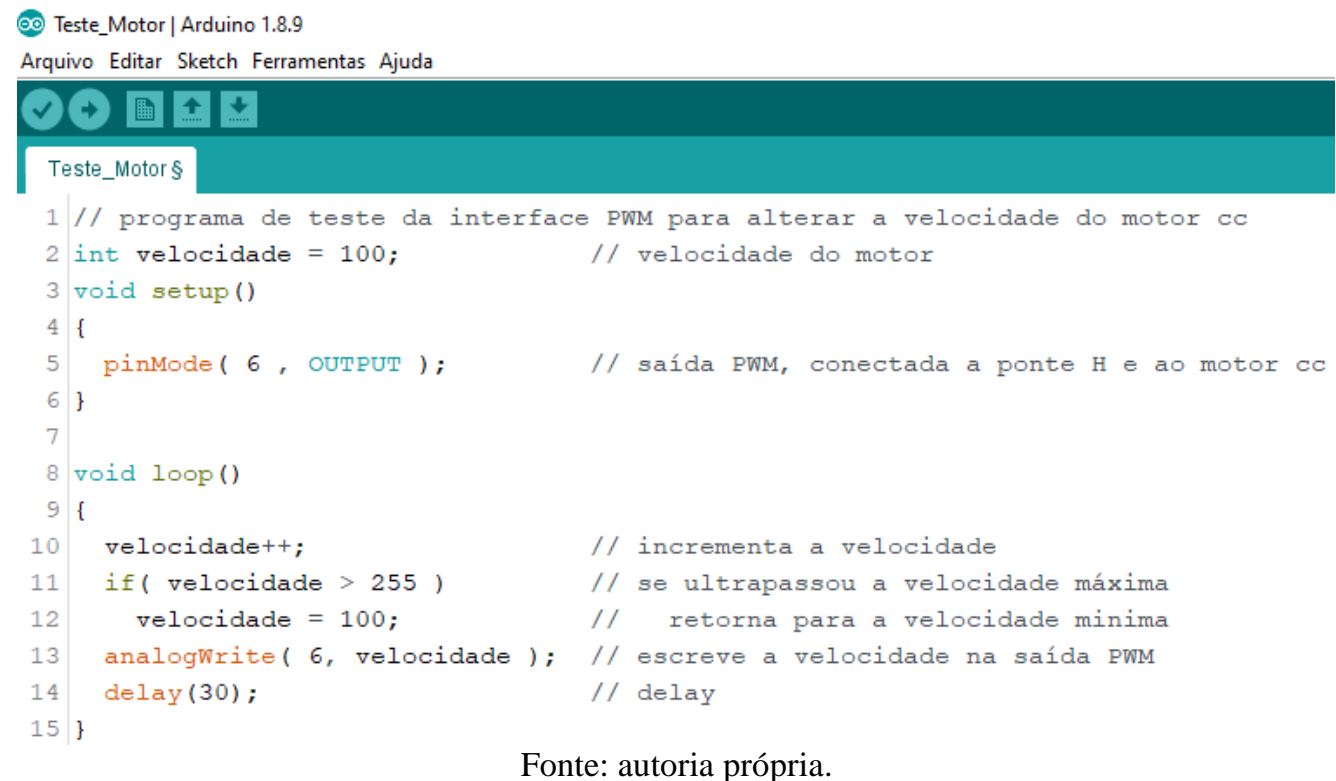




\section{Desafio: como fazer curvas com o chassis de duas rodas?}

O robô seguidor de linha movimenta-se sempre para frente, mas precisa executar curvas, descritas pela faixa na pista. O chassi do robô com controles independentes dos motores pode realizar curvas. Uma diferença de velocidade nos motores provoca o deslocamento em curva. Quanto maior a diferença de velocidade, menor o raio da curva. Esse é o processo para o chassis do robô efetuar curvas. Então é proposto o desafio de pensamento computacional para elaborar um algoritmo para executar esses comportamentos de curva para a esquerda e curva para a direita, para que o robô mantenha-se acompanhando a faixa escura da pista.

\section{Algoritmo para o robô seguidor de linha}

Integrando as funções de sensor de linha e do controle independente dos motores, é necessário desenvolver uma solução autônoma para o robô seguir a linha. $\mathrm{O}$ usuário pode desenvolver o seu algoritmo para o robô seguidor de linha com 1,2, 3 ou mais sensores de linha, alterando a complexidade. Neste projeto utilizamos 2 sensores de linha, como apresenta a figura 8 .

Figura 8 - (a) O sensor de linha da esquerda detectou a faixa, e o robô deve fazer curva para a esquerda,

(b) Os sensores não detectaram a faixa, o robô deve manter a velocidade dos motores,

(c) $\mathrm{O}$ sensor de linha da direita detectou a faixa, e o robô deve fazer curva para a direita.

a)

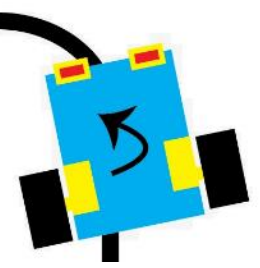

b)

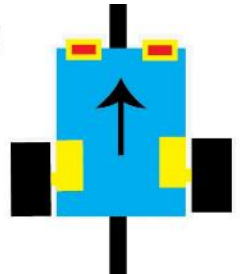

c)

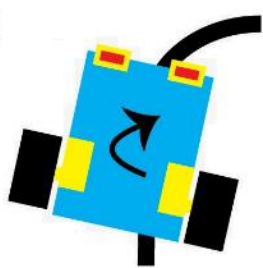

Fonte: autoria própria.

A partir desta etapa, iniciou-se o processo mão na massa, onde as equipes começaram a discutir, elaborar, desenvolver e avaliar as soluções para os problemas apresentados.

\section{Montagem do chassis do robô duas rodas seguidor de linha}

A montagem do chassis, a fixação dos sensores e dos motores, as ligações entre os módulos, tudo soluções elaboradas e testadas pelos calouros. A figura 9 apresenta alguns robôs sendo montados e testados.

Figura 9 - Robôs seguidores de linha sendo montados e testados neste projeto de acolhimento.
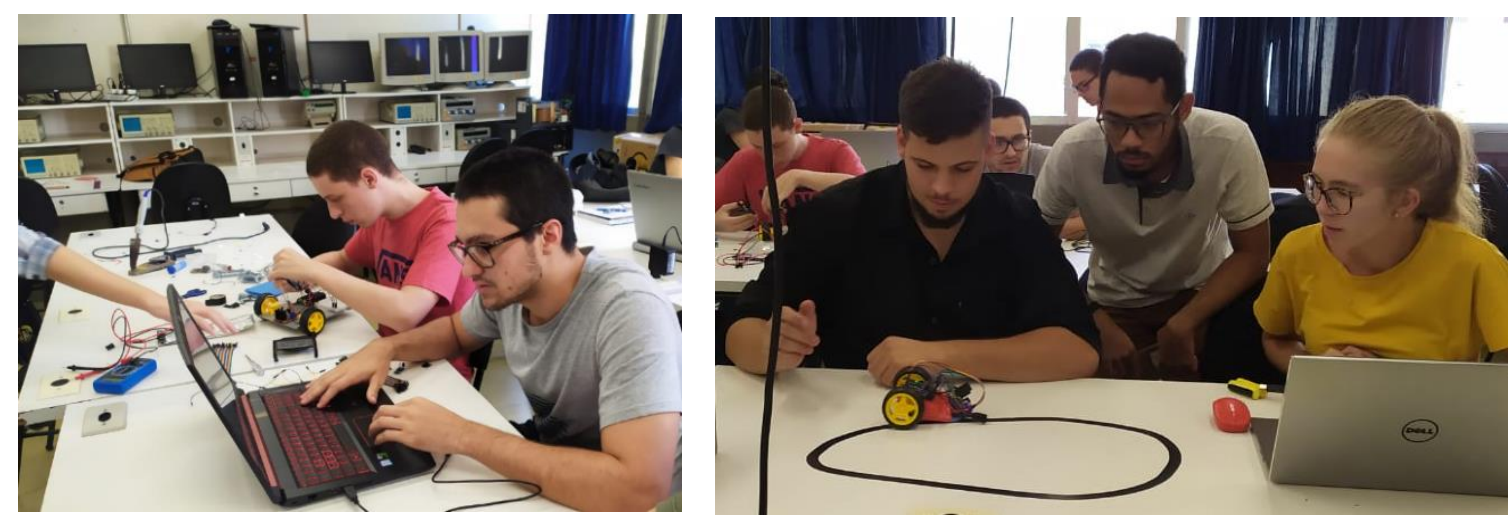

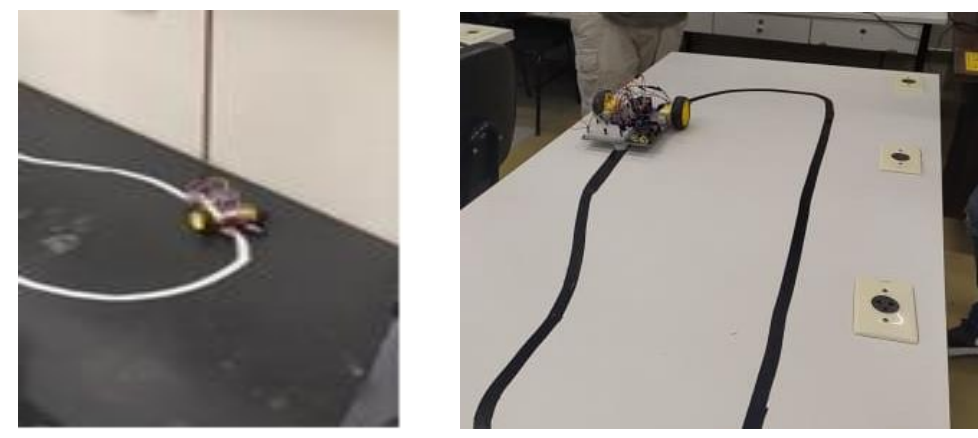

Fonte: autoria própria (com autorização).

\section{Testes, testes, testes}

A parte prática deste projeto foi a observação da execução dos testes dos robôs seguidor de linha desenvolvidos pelas equipes de calouros.

A análise do resultado obtido e a elaboração de um diagnóstico do que ocorreu para estabelecer hipóteses do que deve ser alterado no programa para que execute adequadamente a tomada de decisão e a execução do comando, foi um processo iterativo muito utilizado.

$\mathrm{Na}$ visão de um observador independente, o instrutor viu como as orientações dos monitores e a iteração com os alunos foram convergindo para soluções onde os robôs conseguiam seguir a linha corretamente, diferindo-se na velocidade de progressão.

\section{RESULTADOS}

Como o projeto de extensão teve atividades bem variadas e na parte final é o processo mão na massa, esta capacitação envolveu diversas habilidades pessoais, cognitivas e técnicas, não explícitas no título do projeto, mas exercitadas durante o seu desenvolvimento:

- raciocínio lógico na solução de problemas;

- desenvolvimento de pensamento computacional com a linguagem de programação;

- habilidades gerenciais e técnicas da equipe com planejamento, conhecimento de outros, comunicação verbal, trabalho em equipe;

- habilidade técnica de montagem, de solda, de uso de ferramentas que não estão acostumados, montagem em protoboard, alguma iteração com componentes eletrônicos e módulos a serem interligados;

- iteração com o hardware, projeto e teste de software;

- resiliência, entre outros.

Ao perceber a dificuldade da equipe, ou ao serem chamados pelos calouros, os monitores prestavam os conhecimentos necessários e mostravam o uso correto e seguro de ferramentas e equipamentos necessários para o desenvolvimento.

De um universo de 120 calouros de Engenharia Elétrica e de Engenharia de Controle e Automação, tivemos 13 interessados para participar deste projeto.

\section{CONSIDERAÇÕES FINAIS}

Os calouros entram na universidade com motivação elevada, e levam aqueles baldes de conhecimentos teóricos necessários de Cálculo Diferencial e Integral, Álgebra Linear e Geometria Analítica. O principal objetivo deste projeto de extensão foi mostrar para os 
calouros, que com pouca informação técnica, em nível adequado, eles possuem condições e capacidades de assimilar, elaborar, desenvolver e resolver problemas de engenharia. Sendo um projeto incentivador e motivador para os calouros, permitindo a abertura de novos horizontes. Em paralelo, os calouros conheceram a plataforma de desenvolvimento de baixo custo Arduino, que vai acompanhar a vida acadêmica e talvez parte da vida profissional. Neste projeto de extensão com finalidades didáticas e motivação lúdica (robô seguidor de linha), conseguiram canalizar ideias e pensamentos para resolverem os problemas, e em equipe, desenvolveram uma solução que respondia as necessidades do projeto e suas expectativas pessoais, e a maioria dos robôs conseguiam seguir o circuito descrito pela linha na mesa.

A partir dessa capacitação, os participantes foram muito além de incluir uma palavra no seu dicionário interior e vão prestar mais atenção ao ouvirem a palavra Arduino. Depois da capacitação, vão ver o Arduino como ferramenta de desenvolvimento que vai acompanhá-los pelo curso de Engenharia.

Os componentes eletrônicos e módulos eletrônicos, para o nível de conhecimento dos calouros, foram apresentados como blocos ou caixas pretas com característica funcional, sinal de entrada e sinal de saída. E houve uma ótima compreensão dos conteúdos nesse formato. Nas disciplinas técnicas específicas do curso de engenharia, será apresentado a estrutura interna, modelamento, curvas características, e os detalhes técnicos de projeto, entre outros.

Atividades de pensamento computacional foram desenvolvidas. Procurou-se utilizar similaridades e analogias com as memórias afetivas dos participantes, para que entendessem e conseguissem implementar com os comandos apresentados da linguagem C/Arduino (ARDUINO_1).

Em momentos finais da capacitação foi comentado o estado da tecnologia em caminhões, apresentado pela mídia televisiva em programas específicos, onde montadoras de caminhões apresentam projetos conceito. Assistente de direção para o caminhão seguir, dentro de certas limitações, as faixas brancas da rodovia. Assistente de velocidade onde o motorista não precisa utilizar os pedais, o caminhão mantêm a velocidade de cruzeiro, percebendo a inclinação da pista e a carga que está transportando, e se necessário reduz a velocidade para mantêm a distância do veículo a frente.

Uma continuação deste projeto de extensão para os alunos durante ou após a disciplina de Sistemas de Controle é implementar o algoritmo PID para o robô seguidor de linha e o assistente de velocidade utilizando módulo transdutor de ultrassom.

Uma característica observada nos calouros de hoje, que não ocorria antes de poucos anos atrás, é esse conhecimento de linguagem de programação, do pensamento computacional, e de uso de kits de robótica educacional. Essa característica dos alunos que entram nas engenharias hoje, força ainda mais a necessidade da universidade desenvolver essa acolhida com choques de tecnologia nos calouros, sendo um dos desafios para formar o engenheiro do amanhã.

Esse projeto de extensão é uma ação para incentivar, motivar, descobrir habilidades, oportunizar e capacitar calouros no curso de engenharia. Os esforços da equipe serão em sedimentar e disseminar mais esse projeto, e fortalecer através de esforços continuados nos próximos períodos do curso de Engenharia.

Nas próximas edições deste projeto, pretende-se interagir mais a equipe de monitores com a turma de calouros. E manter contato com essas novas turmas de calouros para acompanhar a iteração da plataforma Arduino com as disciplinas do curso, e para a formação de massa crítica para a renovação de monitores para este projeto de extensão. 


\title{
REFERÊNCIAS
}

ARDUINO_1, Documentação de Referência da Linguagem Arduino, disponível em $<$ https://www.arduino.cc/reference/pt/> , consultado em 23 de julho de 2020.

ARDUINO_2, Site oficial, disponível em <https://www.arduino.cc/>, consultado em 23 de julho de 2020 .

MONK, Simon. Programação com Arduino: Começando com Sketches, 2a . Edição, Bookman, 2017.

PAPERT, Seymour. LOGO: Computadores e Educação, Editora Brasiliense, 1985.

WIKIPEDIA_1, Arduino, disponível em <https://pt.wikipedia.org/wiki/Arduino>, consultado em 24 de julho de 2020.

WIKIPEDIA_2, LEGO Mindstorms, disponível em: <https://pt.wikipedia.org/wiki/LEGO_ Mindstorms>, consultado em 24 de julho de 2020.

WIKIPEDIA_3, LEGO Mindstorms EV3, disponível em <https://en.wikipedia.org/wiki/Lego _Mindstorms_EV3>, consultado em 24 de julho de 2020.

WIKIPEDIA_4, Pensamento Computacional, disponível em <https://pt.wikipedia.org/wiki/ Pensamento_computacional>, consultado em 24 de julho de 2020.

\section{WELCOME AND RECEPTION OF ENGINEERING FRESHMAN WITH CAPACITATION AND HANDS-ON IN AUTONOMOUS ROBOTIC}

\begin{abstract}
This paper introduces a extension project accomplished in the freshman welcome of Control and Automation Engineering and Electrical Engineering in the first semester of 2020. The project was developed by an instructor and a team of monitors and consisted in a capacitation for autonomous robotic in line follower robot. The project had a theoretical and technological exposition with components and electronic modules, and the hands-on step to build, solve the presented problems and make the line follower robot successfully. In a playful way, it was presented engineering problems and were used knowledges, and skills to solve them. We had 13 freshmans that participated in this project. They were divided in 5 teams based in their previous knowledges and skills, and in the end, 3 robots worked rightly.
\end{abstract}

Keywords: freshman welcome. host course. autonomous robotic. line follower robot. risk follower robot. 